\title{
De Ibicaba a Superagui: aproximações entre a imigração dedicada à grande lavora e a colonização havida no Paraná
}

\section{From Ibicaba to Superagui: proximities between the great farm immigration and the colonization that took place in Paraná}

\author{
Caiubi Martins Dysarz*
}

\begin{abstract}
Resumo
O presente artigo pretende acompanhar as vicissitudes do empreendimento colonial de Superagui, iniciado pelo Cônsul Geral da Suíça no Brasil, Carlos Perret Gentil, no ano de 1851. Perret Gentil era empresário na cidade do Rio de Janeiro e, por diversos contatos com cafeicultores paulistas, decidiu por lançar-se à exploração agrícola na região do Superagui, próximo a Paranaguá, declarando como modelo ideal as colônias de parceria iniciadas na grande lavoura de São Paulo. Por mais que o empresário colonizador tivesse por desiderato tais experiências, a colonização levada a cabo no litoral do Paraná afastou-se em grande medida daquelas iniciativas. A investigação do empreendimento e dos agentes históricos que permearam a colonização de Superagui permite-nos delinear aproximações entre a colonização europeia havida no Brasil Meridional e aquela dedicada à substituição de escravos na lavoura do café. Mesmo consideradas muitas vezes antitéticas, ambas as iniciativas de introdução de colonos europeus possuíram muitas ligações e partilharam de um destino comum: a modificação de arranjos de trabalho entre proprietários de terra e trabalhadores foreiros ou assalariados.
\end{abstract}

Palavras-chave: Colonização no Paraná; Sistema de parceria; Colônia de Superagui; Carlos Perret Gentil;

\begin{abstract}
The present article intends to investigate the transformations of the colonial enterprise of Superagui, started by the General Consul of Switzerland in Brazil, Carlos Perret Gen-til, in the year 1851. Perret Gentil was enterprising in the city of Rio de Janeiro and by many contacts with paulistas farmers, he decided to aim at the agricultural exploration in the Superagui peninsula, declaring as an ideal model the sharing system colonies, implemented in the São Paulo's great farming. For more the colonizer enterprising had as design such experiences, the colonization initiated in Paraná's shores distanced itself in a large way
\end{abstract}

* Mestre em História pela UFPR. E-mail: caiubi_martins@hotmail.com 
from those initiatives. The investigation of the enterprise and the historical agents that pass through the colonization of Superagui allow us to outline proximities between the European colonization that took place in the south of Brazil and the other one, dedicated to the replacement of slaves in the coffee plantation. Even considered the many times each other as opposites, both initiatives of introduction of Europeans colonists had much liaisons and shared a common fate: the changes of work arrangement between landlords and renters or wage earner workers.

Keywords: Paraná's Colonization; Sharing System; Superagui Colony; Carlos Perret Gentil;

\section{Introdução}

Defende-se que os empreendimentos de colonização havidos na região do Paraná, a partir da segunda metade do século XIX, distinguiam-se largamente da imigração destinada à grande lavoura exportadora, cujo principal objetivo foi angariar trabalhadores livres para cafeicultura. As colônias de estrangeiros estabelecidas na região supracitada estariam voltadas para o fornecimento de gêneros de subsistência ${ }^{1}$ e seriam formadas por colonos pequenos proprietários. Essa antítese é corroborada por diferentes estudos e está longe de ser refutada. ${ }^{2}$ Porém, a análise de trajetórias individuais e empreendimentos de colonização específicos aponta para imbricações entre as duas iniciativas, e, por momentos, quase uma simbiose.

Tal foi o caso da Colônia de Superagui, empreendimento iniciado na região homônima do litoral paranaense em 19 de outubro de 1851, por iniciativa do então Cônsul Geral da Suíça no Brasil, Carlos Perret Gentil. o fundador do núcleo colonial afirmou ser um entusiasta do sistema de parceria, praticado

\footnotetext{
${ }^{1}$ BALHANA, Altiva Pilatti. Política Imigratória do Paraná. In: BALHANA, Altiva Pilati. Un Mazzolino de Fiori, vol. I / Cecilia Maria Westphalen (org.). Curitiba: Imprensa Oficial, 2002, p. 367; DRABIK, Belquis Ribeiro. GONÇALVES, Marcos. Notas sobre política imigratória na Província do Paraná. In: BOSCHILIA, Roseli (Org.). Reconstruindo Memórias: os Poloneses do Santo Inácio. Curitiba: Universidade Tuiuti do Paraná, 2004, p. 26-29; SANTOS, Carlos Roberto Antunes do. História da Alimentação no Paraná. Curitiba: Fundação Cultural, 1995, p. 103; NADALIN, Sérgio Odilon. Imigrantes de Origem Germânica no Brasil: Ciclos Matrimoniais e Etnicidade. Curitiba: Aos Quatro Ventos, 2001, p. 174.

${ }^{2}$ BALHANA, Altiva Pilatti; MACHADO, Brasil Pinheiro; WeSTPHALEN, Cecília Maria. Alguns Aspectos Relativos Aos Estudos de Colonização e Imigração. In: BALHANA, Altiva Pilati. Un Mazzolino de Fiori, vol. I / Cecilia Maria Westphalen (org.). Curitiba: Imprensa Oficial, 2002, p. 245; MENDOÇA, Joseli Maria Nunes. Revisitando a história da imigração e da colonização no Paraná provincial. In: Antíteses, Londrina, v.8, n.16, p.204-226, jul./dez. 2015, p. 207; SEYFERTH, Giralda. Imigração e Cultura no Brasil. Brasília: Editora UNB, 1990, p. 14.
} 
nas propriedades cafeicultoras paulistas, e decidiu criar seu empreendimento a partir das observações lá colhidas. Acompanhar as transformações no projeto original do empreendimento havido às margens da Baía de Paranaguá é o objetivo principal deste trabalho. Como fio condutor de nossa análise, relacionar-se-ão os empreendimentos de colonização europeia havidos em âmbito nacional com a trajetória de cônsul suíço Perret Gentil; após, o foco será suas observações da imigração na lavoura paulista e o discurso em defesa de tais iniciativas; posteriormente, haverá a observação do estabelecimento do núcleo colonial na Baía de Paranaguá; por fim, serão sugeridas hipóteses para explicar a diferença entre o discurso proclamado e a organização da Colônia de Superagui.

\section{Projetos de imigração e colonização no Império do Brasil na primeira metade do Século XIX}

A entrada de elementos europeus na América Portuguesa durante o período colonial não foi substancialmente estimulada pela coroa portuguesa, ${ }^{3}$ porém, por todo o século XVIII, mobilizações de maior monta de portugueses e projetos de colonização oficial ocorreram, como as imigrações em função da atividade mineradora ${ }^{4}$ e a colonização de casais açorianos. ${ }^{5}$ A tentativa oficial tinha objetivos defensivos e de mudança da crença na degradação do trabalho manual, características que vão pontuar as iniciativas posteriores ao decreto real de 1808, que permitia a súditos não-portugueses a aquisição de sesmarias no território brasileiro. ${ }^{6}$ Já no período pós-Independência, as necessidades de recrutamento de tropas são conjugadas às premências de melhoria na agricultura e ocupação do território. ${ }^{7}$

\footnotetext{
${ }^{3}$ BALHANA, op. cit., p. 245.

${ }^{4}$ KLEIN, Herbert. Migração Internacional na História das América. In: FAUSTO, Boris (org.). Fazer a América. São Paulo: EDUSP, 1999, p. 19; NADALIN, Sergio Odilon. Paraná: Ocupação do Território, População e Migrações. Curitiba: SEED, 2002, p. 56.

${ }^{5}$ MACHADO, Paulo Pinheiro. Colonizar para Atrair: A Montagem da Estrutura Imperial de Colonização no Rio Grande do Sul (1845-1880). 165 f. Dissertação (Mestrado em História). Instituto de Filosofia e Ciências Humanas, Unicamp, Campinas, 1996, p. 10; BALHANA, Altiva Pilatti. Política Imigratória no Brasil Meridional. In: BALHANA, Altiva Pilati. Un Mazzolino de Fiori, vol.III / Cecilia Maria Westphalen (org.). Curitiba: Imprensa Oficial, 2002, p. 131.

${ }^{6}$ BALHANA, op. cit., p. 245; LAZZARI, Beatriz Maria. Ideologia e Imigração: reação do parlamento brasileiro à política de imigração e colonização (1850-1875). Porto Alegre: Escola Superior de Teologia de São Lourenço de Brindes; Universidade de Caxias do Sul, 1980, p. 31.

${ }^{7}$ OBERACKER JR, Carlos H. A Contribuição Teuta à Formação da Nação Brasileira. Rio de Janeiro: Presença, 1985 , p. 172; 177-179.
} 
Os projetos de colonização levados a cabo pelo Império foram objeto de inúmeras críticas de parlamentares ligados à agricultura de exportação, como o senador paulista Nicolau Pereira de Campos Vergueiro, pelo fato de serem considerados empreendimentos inócuos e geralmente fracassados. $\mathrm{O}$ fato de tais iniciativas fornecerem terras aos imigrantes, enquanto havia necessidade de mão de obra para a agricultura, foi outro ponto destacável das críticas. ${ }^{8}$ Em 1830, o parlamento imperial proibiu o gasto com projetos de colonização, retomando-o apenas em $1834,{ }^{9}$ bem como o engajamento de regimentos estrangeiros. ${ }^{10}$

Passada a década de 1830 - talvez o período mais crítico para a imigração européia no Brasil ${ }^{11}$ - o decênio de 1840 assiste ao recrudescimento dos projetos de colonização. Entre estes, encontrava-se um de autoria do mesmo senador Vergueiro, que introduziu em sua propriedade de Ibicaba dezenas de portugueses provenientes da região do Minho, ${ }^{12}$ adotando com eles o regime de trabalho denominado de parceria. O cerne do regime consistia na divisão do montante proveniente da venda do café entre o fazendeiro e colono europeu na razão de $50 \%$. Além disso, fornecia-se um pequeno lote na grande propriedade para que o trabalhador pudesse cultivar gêneros; em caso de sua comercialização, o fazendeiro retinha metade do ganho pecuniário. Por fim, uma cadeia de dívidas atrelava o colono ao grande proprietário, e sua liquidação era obrigatória para o término dos contratos. ${ }^{13}$

Porém, a experiência é desfeita pelo envolvimento de Nicolau Vergueiro na Revolta Liberal de $1842 .{ }^{14}$ Apenas em 1846, com apoio do Governo Imperial, o senador paulista retomaria as atividades para ingresso de colonos europeus como trabalhadores sob a égide de grandes fazendeiros. Para isso, criou a

\footnotetext{
${ }^{8}$ LAZZARI, op. cit., p. 33, 49. PETRONE, Maria Thereza Schorer. O Imigrante e a Pequena Propriedade (1824-1930). São Paulo: Brasiliense, 1982, p. 22. Sobre as cisões no interior da elite imperial e o papel dos fazendeiros no Império Cf. ALENCASTRO, Luís Felipe de; RENAUX, Maria Luiza. Caras e Modos dos migrantes e imigrantes. In: ALENCASTRO, Luís Felipe de (org.) História da vida privada no Brasil - volume 2. São Paulo: Cia das Letras, 1997, p. 295-299.

${ }^{9}$ BALHANA, op. cit., p. 246.

${ }^{10}$ LAZZARI, op. cit., p.49; MACHADO, op. cit., p. 15.

${ }^{11}$ NADALIN, Paraná: Ocupação do Território..., op. cit., p. 66; RIBEIRO, Gladys Sabina. A Liberdade em Construção: Identidade Nacional e conflitos anti lusitanos no Primeiro Reinado. Rio de Janeiro: FAPERJ, 2002, p. 163.

${ }^{12}$ WITTER, José Sebastião, A revolta dos parceiros. São Paulo: Brasiliense, 1986, p. 26; DEAN, Warren. Rio Claro: Um Sistema Brasileiro de Grande Lavoura 1820-1920. Rio de Janeiro: Paz e Terra, 1977, p. 97.

${ }^{13}$ HOLLANDA, Sérgio Buarque de. As colônias de parceria. In: História Geral da Civilização Brasileira. II. O Brasil Monárquico 3. Reações e Transações. Rio de Janeiro: Bertand Brasil, 2004, p. 246-247; HOLLOWAY, Thomas H. Imigrantes para o café: Café e sociedade em São Paulo, 1886-1934. Rio de Janeiro: Paz e Terras, 1984, p. 112.

${ }^{14}$ WITTER, op. cit., p. 26; DEAN, op. cit., p. 97.
} 
Vergueiro e Cia no mesmo ano, com sede na cidade de Santos, sob a presidência de seu filho, José Vergueiro. ${ }^{15}$ É por essa época que o primogênito do senador Nicolau Vergueiro iria entrar em contato com aquele que talvez fosse o maior propagandista e defensor das empresas da família paulista: o Cônsul Geral da Confederação Suíça no Brasil, Carlos Perret Gentil.

\section{A relação do cônsul geral da Suíça no Brasil com a imigração para a cafeicultura paulista}

Carlos Perret Gentil nasceu em 19 de outubro de 1814, na cidade de Fleurier, no Cantão de Neuchatel, na Suíça, e emigrou para o Brasil por volta dos anos de 1835 e $1836 .{ }^{16}$ Uma vez que não dispomos de relatos sobre sua emigração, o contexto do país alpino à época auxilia-nos a formular hipóteses para tal. ${ }^{17}$ Após as guerras napoleônicas, formam-se na Suíça diversas casas de comissão, que realizavam comércio transatlântico por meio do agenciamento de mercadorias, cujo rendimento provinha de comissões sobre as vendas daí seu nome. É a partir de 1830 que tais empresas suíças se estabelecem no Brasil, representadas por homens jovens com o intuito de fazer fortuna. ${ }^{18}$

Tal contexto explicaria a imigração de Perret Gentil no Brasil, na qualidade de comerciante, algo corrente aos europeus imigrados no Rio de Janeiro à época. ${ }^{19} \mathrm{O}$ suíço fora sócio da Terrisse \& Cie, casa de comissão fundada por três irmãos genebrinos que se instalaram no Brasil em 1815 e iniciaram suas atividades em 1820, com operação na cidade fluminense. ${ }^{20}$ Enquanto esteve a cargo da empresa, Perret Gentil fora nomeado cônsul da Confederação Suíça em 1838, com apenas 23 anos. Sob sua influência, elevou a representação existente no Rio de Janeiro em consulado geral no ano de 1840. Em seu período consular, deixou livros de registro repletos de lacunas, além de ser acusado de

\footnotetext{
${ }^{15}$ VERGUEIRO, Nicolau. Correspondência ao Presidente da Província de São Paulo, Manoel Fonseca de Lima e Silva. Santos, $1^{\circ}$ de agosto de 1846. Arquivo Público do Estado de São Paulo (AESP). Acervo Império (1822 a 1889) - Colônia: CO7213.

${ }^{16}$ SILVA, Joaquim Félix da. Certidão de naturalização do suiç̧o Carlos Perret Gentil. Paranaguá, 16 de janeiro de 1858. Arquivo Público do Paraná, AP - 54, p. 79-83.

${ }^{17}$ Giovanni Levi explicitou a respeito da utilização do contexto histórico para compreender trajetórias individuais, conferir: LEVI, Giovanni. Usos da Biografia. In: FERREIRA, Marieta de Moraes \& AMADO, Janaina (orgs.). Usos e abusos da história oral. Rio de Janeiro: Editora da FGV, 1996, p. 175.

${ }^{18}$ VEYRASSAT, Béatrice. Les Suisses et la Suisse au Brésil (1817-1930). Le renouvellement des communautés de'affaires ou le recul de l'influence économique de la Suisse française. Etudes et Sources, 1995, oㅡ 21, p. 12-13. Disponível em: "http://www.amtsdruckschriften.bar.admin.ch/viewOrigDoc. do?id=80000185". Acesso em 08/02/2012.

${ }^{19}$ RIBEIRO, op. cit., p. 186.

${ }^{20}$ VEYRASSAT, op. cit., p. 14.
} 
criar cargos de vice-cônsul sem a autorização de seu país de origem, de papel irrelevante e mesmo em troca de alguma retribuição pecuniária. ${ }^{21}$

A Terrisse \& Cie encerrou suas atividades em 1844. Em vista disso, o agora cônsul fundou em 1845 na cidade fluminense de Campos uma fábrica de garrafas e lâmpadas à base de gás hidrogênio líquido, utilizadas na iluminação pública e privada. ${ }^{22}$ Nos anos seguintes, seus produtos foram adotados no teatro e na iluminação pública do município, ${ }^{23}$ e, na tentativa de expandir mercado, o cônsul suíço encontrou uma personalidade paulista que o influenciaria em seus negócios futuros.

Em 1846, em viagem num vapor em direção a Santos, Perret Gentil conheceu José Vergueiro, o presidente da Vergueiro e Cia, oportunidade na qual versaram largamente sobre colonização e utilização do trabalho livre na lavoura de café em oposição ao escravo. Posteriormente, em 1847, Gentil visitou a propriedade da família paulista de Ibicaba, lavrada por 215 escravos e sete famílias de portugueses remanescentes da empreitada de 1840, estes sob o sistema de parceria. O nível de vida em que se encontravam os portugueses impressionou bastante Perret Gentil, que fora informado por José Vergueiro que a introdução de trabalhadores europeus não ficaria limitada a essa tentativa. No ano seguinte, várias famílias viriam financiadas pelo fazendeiro, cujo reembolso do investimento seria feito pelos próprios colonos. ${ }^{24}$

Tal é a história contada por Carlos Perret Gentil de como passou a se interessar pelos assuntos de colonização em seu livro "A Colônia Senador Vergueiro: Considerações", opúsculo dedicado ao seu anfitrião em Ibicaba. ${ }^{25}$ O livro trata de dois temas principais: primeiro, as observações a respeito da colonização no Brasil, concluindo-se que o sistema praticado por Vergueiro seria o único passível de sucesso; e, segundo, o estabelecimento dos alemães introduzidos em 1847 e sua situação alguns anos depois. Com os auxílios provenientes dos cofres imperiais, a Vergueiro e Cia conseguiu angariar 423 colonos hamburgueses, iniciando em julho do mesmo ano as atividades da Colônia

\footnotetext{
${ }^{21}$ TSCHUDI, Johann Jakob Von. Rapport de Mr. de Tschudi, Envoyé extraordinaire de la Confédération suisse au Brésil, sur les Consulats suisses dans le dit pays. Feuille Fédérale Suisse. Ano 13, Volume 3, $\mathrm{N}^{\circ} 63$, 31 de dezembro de 1861, p. 277- 281;

${ }^{22}$ GENTIL, Carlos Perret. Requerimento a S.M.I., solicitando privilégio exclusivo para fabricar gás hidrogênio líquido para iluminação. Rio de Janeiro. 1845. Biblioteca Nacional - Seção de Manuscritos - documentos biográficos. Localização: C - 0777, 069.

${ }^{23}$ RODRIGUES, Herve Salgado. Na taba dos goytacazes. Niterói: imprensa oficial, 1988, p. 56; 60.

${ }^{24}$ GENTIL, Carlos Perret. A Colonia Senador Vergueiro - Considerações. Santos: Typographia Imparcial de F. M. R. de Almeida, 1851, p. 31-33.
}

${ }^{25}$ Ibidem, p. 3; 31. 
Senador Vergueiro, na circunscrição da propriedade de Ibicaba. ${ }^{26}$ Em 1851, ano da publicação do livro, Gentil verificou o estado em que se encontravam os colonos introduzidos, fornecendo-nos impressões quase nababescas da vida dos alemães no empreendimento.

Primeiro, descrevera a opulência das habitações dos colonos, que teriam muitos itens que não se encontrariam nas casas de "aldeões ricos" europeus, denunciando o "gráo de abastança" a que chegaram essas famílias. ${ }^{27}$ Encontrara famílias contentíssimas e felizes, com víveres em fartura, que não sofriam frio e nem miséria. ${ }^{28}$ Durante sua estada em Ibicaba, Perret Gentil encontrou um lavrador que possuía treze escravos pedindo para ser admitido na colônia, uma vez que "no seu sitio nunca tinha podido chegar a ganhar tanto quanto um colono bem trabalhador". ${ }^{29}$ Por fim, as dívidas contraídas pelos colonos seriam facilmente quitadas em apenas três anos. ${ }^{30}$

Enquanto autor, Perret Gentil acalentava que seus possíveis leitores se apropriassem dessas observações, com o objetivo de lhes incutir uma série de atitudes e comportamentos. ${ }^{31} \mathrm{O}$ primeiro deles era tornar a propriedade paulista atraente aos possíveis emigrantes europeus, e o livro supracitado e suas derivações em línguas europeias foram utilizadas com esse intuito. Os relatos do famoso colono Thomas Davatz e do enviado suíço Johann Jakob Von Tschudi apontam para essa conclusão. Davatz imigrou no Brasil em função dos escritos do cônsul suíço e esteve decidido a questioná-lo pessoalmente sobre as maravilhas que escrevera. Tschudi afirmara que Gentil apresentou o sistema de pareceria de maneira muito favorável, conseguindo assim atrair numerosos europeus atingidos pelo pauperismo. ${ }^{32}$

Entretanto, não bastava apenas persuadir os imigrantes do sucesso da empreitada - era necessário convencer os potenciais clientes da firma

\footnotetext{
${ }^{26}$ VERGUEIRO, op. cit.

${ }^{27}$ GENTIL, op. cit., p. 60.

${ }^{28}$ Ibidem, p. 63-64.

${ }^{29}$ Ibidem, p. 66.

${ }^{30} \mathrm{Ibidem}$, p. 90.

${ }^{31} \mathrm{~A}$ respeito das atitudes de leitores frente às informações veiculadas por um livro, bem como os objetivos destas, conferir: CHARTIER, Roger. A aventura do livro: do leitor ao navegador: conversações com Jean Lebrun. São Paulo: Imprensa Oficial do Estado de São Paulo: Editora UNESP, 1998, p.77; _._.. Cultura escrita, literatura e história: Conversas de Roger Chartier com Carlos Aguirre Anaya, Jesús Anaya Rosique, Daniel Goldine Antonio Saborit. Porto Alegre: ARTMED Editora, 2001, p. 24, 113-117; ___. Lectures et Lecteurs dans La France d'Ancien Régime. Paris: Éditions Du Seuil, 1987, p. 11, 45.

${ }^{32}$ DAVATZ, Thomas. Memórias de um colono de Brasil (1850). São Paulo: Editora da Universidade de São Paulo, 1980, p. 149; TSCHUDI, Johann Jakob Von Tschudi. Viagem às Províncias do Rio de Janeiro e São Paulo. Biblioteca Histórica Paulista. São Paulo: Livraria Martins Editora S. A., 1953, p. 140.
} 
Vergueiro: os diversos fazendeiros paulistas, escravocratas empedernidos que ainda estavam pouco dispostos a aceitar o trabalho de colonos europeus. Perret Gentil argumentava que os fazendeiros poderiam lucrar muito mais com o trabalho livre na base da divisão da venda do café do que com o trabalho escravo. José Vergueiro tinha por fim convencer outros proprietários, uma vez que mediante seu exemplo daria "uma prova incontestavel contra a opinião geral, de que introduzindo uma população branca que trabalhasse a meias com o proprietario, [...] este ganhava no augmento de valor das terras e obtinha safras muito maiores...". ${ }^{33}$

Nesse sentido, acusações são dirigidas aos grandes proprietários, que são considerados, em parte, responsáveis pelo insucesso da colonização no Brasil, por seu tratamento rude com os colonos. ${ }^{34} \mathrm{O}$ fim do tráfico de escravos e da escravidão, já vislumbrado por Perret Gentil, tornava-se mais uma justificativa para a introdução de imigrantes europeus; entretanto, esbarrava na convicção dos grandes fazendeiros, de que "os colonos não podem prestar os mesmo serviços dos escravos, e que a introducção d'aquelles tende a mudar totalmente seus habitos, porque de necessidade deve ser todo diverso o regimen a seguir com elles". ${ }^{35}$ Perret Gentil defendia que a produção decorrente da divisão da venda do café poderia ser vantajosa aos fazendeiros, uma vez que, com o trabalho escravo, a produção ficaria estacionária, ao passo que com a introdução de colonos, estimulados por possíveis ganhos, e com compra de novas terras, sua safra deveria apenas aumentar:

(...) quando se falla á maior parte dos fazendeiros na partilha dos productos com os colonos, parece que isto equivaleria a arrancar-lhes a alma [...] Calculam sómente que tem - tantos negros os quaes lhe dão um rendimento de - tantas arrobas - ; e por conseguinte substituindo-os por colonos, e dividindo os productos, apenas teriam metade d'aquelle redito ${ }^{36}$

A insistência nos ganhos que os cafeicultores poderiam obter com a utilização dos colonos europeus, bem como nas qualidades desses trabalhadores (brancos, estáveis, industriosos...), tinha o intuito claro de convencer outros proprietários não só a adotar o sistema proposto por Vergueiro, como também a contratá-lo para a remessa de tais colonos, como ocorre na década

\footnotetext{
${ }^{33}$ GENTIL, op. cit., p. 33.

${ }^{34}$ Ibidem, p. 6.

${ }^{35}$ Ibidem, p. 19.

${ }^{36}$ Ibidem, p. 27-28.
} 
de $1850 .{ }^{37}$ De fato, nesse decênio são criadas 42 colônias no interior de fazendas particulares em São Paulo. ${ }^{38}$ Entretanto, a resistência dos fazendeiros em substituir os trabalhadores escravos por colonos, mesmo europeus, persistiria por décadas a fio, mesmo que talvez fosse mais caro obter um escravo do que trazer uma família oriunda da Europa. ${ }^{39}$

O sistema de colonização posto em prática pelos Vergueiro seria tão passível de sucesso que o próprio apologista da empresa tornar-se-ia agricultor, fazendo uso das experiências obtidas pela família paulista. É o que nos afirma o próprio Perret Gentil, que, encontrando-se enfermo para dar andamento a sua fábrica de gás hidrogênio em Campos, pretendia dedicar-se "a agricultura sobre as bases do seu systema", ${ }^{40}$ atraindo trabalhadores novos, sendo assim útil a sua nova pátria. Depois de ter averiguado as causas do fracasso de todas as empresas de colonização, teve por plano estabelecer uma companhia para tal, cujo capital proviria da venda de ações. Tal companhia deveria comprar uma grande extensão de terra, com escravos ou não, para receber um grande número de colonos; cada família receberia um terreno para explorar de dimensões em correspondência com suas forças, devendo dividir seus produtos com a administração colonial; por fim, as famílias seriam responsáveis pelos custos de seu transporte e não poderiam deixar a empresa sem antes quitar suas dívidas. ${ }^{41}$

Perret Gentil tinha por objetivo iniciar um empreendimento imigrantista que fizesse uso do esquema de trabalho livre posto em prática na grande lavoura, aproximando-se, dessa forma, dos desígnios e projetos de tais empreendimentos. Em função de os fazendeiros do Oeste Paulista empregarem colonos europeus como simples trabalhadores, atacavam no legislativo do Império os fornecimentos de terras a tal contingente, uma vez que se deveria atender às necessidades prementes do setor mais produtivo da economia nacional, abalado em função do fim do tráfico de escravos. ${ }^{42}$ As tentativas de colonização de áreas inexploradas ou parcialmente exploradas por colonos europeus como

\footnotetext{
${ }^{37}$ COSTA, Emília Viotti da. Da Senzala à Colônia. São Paulo: Fundação Editora da UNESP, 1998, p.125

${ }^{38}$ OLIVEIRA, José Joaquim Machado de. Relação das colônias existentes em 1860. Repartição das Terras Públicas e Colonização na Província de São Paulo. São Paulo, 13 de dezembro de 1861. Arquivo Nacional - Série Agricultura: *IA 87 (códice).

${ }^{39}$ COSTA, op. cit., p. 84

${ }^{40}$ GENTIL, op. cit., p. 33.

${ }^{41}$ Ibidem, p. 21-23.

${ }^{42}$ BALHANA, op. cit., p. 240; LAZZARI, op. cit., p. 69.
} 
pequenos proprietários ${ }^{43}$ eram empreendimentos dispendiosos com resultados de pouca monta, cujos capitais seriam melhor empregados na imigração destinada aos grandes latifúndios. Mesmo quando o emprego da mão de obra europeia se restringia à lavoura, ainda havia discordâncias no financiamento de sua vinda pelo Governo Imperial, manifestada pela oposição do legislativo das províncias do Norte do Império. ${ }^{44}$ Entretanto, por mais próximo que fosse o projeto de Perret Gentil dos empreendimentos da grande lavoura, sofreria transformações que, no fundo, distanciavam-se de grande parte dos ideais defendidos pelos cafeicultores do Oeste Paulista, aproximando-se muito da colonização que considerava inócua ou improdutiva.

\section{A fundação da Colônia de Superagui sob os auspícios da grande lavoura}

Vimos acima o afã de Perret Gentil em tornar-se agricultor sob "as bases do sistema Vergueiro", bem como seu plano de formar uma companhia para tratar dos assuntos de colonização. No mesmo ano em que publicara suas opiniões a respeito da fazenda de Ibicaba, lançara-se em seu próprio projeto de colonização, no litoral da $5^{\mathrm{a}}$ Comarca da Província de São Paulo. Por volta do mês de outubro de 1851, o cônsul desembarcou em Paranaguá acompanhado de 12 colonos suíços, que se dirigiram para a península do Superagui, distante algumas léguas da cidade portuária. O núcleo pioneiro da futura Colônia de Superagui estabeleceu-se na região em 19 de outubro de $1851 .{ }^{45}$

A referida circunscrição provincial já estava em processo avançado de elevação à categoria de província, projeto acalentado desde os idos de D. João VI e efetivado pelos esforços de João da Silva Machado, o Barão de Antonina, em angariar a lealdade dos liberais locais à Coroa durante a Revolta Liberal de 1842. A antiga $5^{\circ}$ Comarca de São Paulo passaria a ser a nova Província do Paraná, criada em 29 de agosto de $1853{ }^{46}$ Nesse ínterim, a nova região experimentou esforços de colonização, animados e acompanhados pelo mesmo Barão de Antonina que, em 1816 e 1828, instalaria respectivamente açorianos e alemães na região da Capela da Mata, um dos ramais do Viamão,

\footnotetext{
${ }^{43}$ BALHANA, op. cit., p. 266.

${ }^{44}$ LAZZARI, op. cit., p. 54; 59; 65.

${ }^{45}$ GENTIL, Carlos Perret. Mappa da Colonia de Superaguy no ano de 1858. Superagui, 3 de junho de 1858. Arquivo Público do Paraná, AP - 59, p. 20-24.

${ }^{46}$ OLIVEIRA, Ricardo Costa de. O silêncio dos Vencedores: genealogia, classe dominante e estado no Paraná. Curitiba: Moinho do Verbo, 2001, p.139-147; BELOTO, Divonzir Lopes. A criação da Província do Paraná: a emancipação conservadora. 102 f. Dissertação (Mestrado em Economia). Departamento de Economia da Pontifícia Universidade Católica de São Paulo, São Paulo, 1990, p. 55-68.
} 
constantemente atacada por índios, formando-se na última oportunidade a colônia de pequenos agricultores de Rio Negro. ${ }^{47}$

Outro ensaio de colonização, quase coetâneo ao de Carlos Perret Gentil, foi o do médico francês João Maurício Faivre, a Colônia Thereza, às margens do Rio Ivaí, no interior da futura província, iniciada com 64 franceses, em 18 de fevereiro de 1847. Argumentando que a agricultura seria a fonte de riquezas de um país e que as tentativas de colonização no Brasil tinham fracassado nesse objetivo, Faivre foi animado pela Imperatriz Thereza Cristina a constituir um núcleo que lograsse ter sucesso nessas atividades por meio de um novo sistema de colonização. O projeto de Faivre, ao menos em tese, era dotado de certo idealismo, ${ }^{48}$ uma vez que a localização remota tinha por objetivo deixar os colonos afastados da atividade mercantil e dos grandes centros de comércio, considerados como incompatíveis com uma colônia agrícola. O contato com vendedores e com proprietários de escravos deveria ser evitado a todo custo. ${ }^{49}$

Faivre tinha recebido por empréstimo 6 contos de réis da Imperatriz e despendido 4 contos do próprio patrimônio, tornando a pedir em novembro de 1847 mais recursos uma vez que poderiam "os actuaes habitantes da Colonia Thereza desesperando de sua sorte, abandona[r] a recem nascida povoação". ${ }^{50}$ De fato, meses depois restariam apenas seis dos franceses imigrados. 0 diretor da colônia admitiu que não selecionara os imigrantes mais aptos para o projeto, mesmo tendo-lhes ofertado terrenos e auxílios gratuitos. Posteriormente, angariou brasileiros de Castro e Guarapuava "muito mais proprios para trabalhar e viver nos sertões do que os estrangeiros". As terras foram cedidas gratuitamente a tais colonos, sob a obrigação de que as lavrassem. Faivre lembrava ao Presidente de Província que sua empresa era, "motivada por hum espirito de caridade e como bem longe d'huma especulação financeira" ${ }^{51}$

\footnotetext{
${ }^{47}$ BALHANA, Política Imigratória do Paraná..., op. cit, p. 363.

${ }^{48} \mathrm{~A}$ afirmação de que Faivre pudesse ter se inspirado em ideias socialistas utópicas parece pouco confiável. Mesmo os argumentos mostrados por Josué Correa Fernandes, de que a constituição da Colônia Thereza, pelo fato de ser afastada, agrícola e valorizar o trabalho executado com as próprias mãos, tivesse sofrido influência das ideias socialistas, carece de comprovação, uma vez que os ideais referidos eram a base de todas as colônias formadas no Império. FERNANDES, Josué Corrêa. Saga da Esperança: socialismo utópico à beira do Ivaí. Curitiba, Imprensa Oficial 2006, p. 100-107.

${ }^{49}$ FAIVRE, João Maurício. Requerimento encaminhado ao Ministério do Império, solicitando uma ajuda ate a primeira colheita, os 64 colonos agricultores que formam a colonia Tereza, fundada por ele, as margens do rio Ivaly, Sao Paulo, proximo ao porto de Paranagua. Biblioteca Nacional - Documentos Biográficos, C - 0090, 022 ํo 005.

${ }^{50}$ Idem.

${ }^{51}$ FAIVRE, João Mauricio. Correspondência enviada ao Presidente de Província do Paraná, Francisco Liberato de Mattos. Colônia Thereza, 4 de março de 1858. Arquivo Público do Paraná, AP 74, p. 99-102.
} 
Como observado acima, as tentativas de colonização na região da futura Província do Paraná pautavam-se pela introdução de colonos europeus como pequenos proprietários e em regiões ermas, projetos diferentes da imigração destinada ao Oeste Paulista, cujo fim era suprir de mão de obra a agricultura de exportação. $O$ empreendimento de Perret Gentil, por mais que este afirmasse, distanciou-se da experiência que o estimulou, tornando-se análogo aos projetos então encampados na nova Província.

o primeiro desafio aos desígnios do empreendedor suíço seria a aquisição da localidade em que instalou seu núcleo pioneiro, a península de Superagui, propriedade particular do inglês David Stevenson. No ano de 1815, Stevenson adquiriu as terras de Superagui, então pertencentes à região de São Paulo. Na qualidade de senhor absenteísta, estimulou a cafeicultura em sua propriedade, cuja escravaria alcançou 48 indivíduos, empregados no trato de 28 mil cafeeiros.$^{52} \mathrm{Na}$ década de 1830 , as atividades foram interrompidas. A coroa inglesa determinou que seus súditos emancipassem os escravos sob sua custódia, tal como Stevenson, negociante em Londres. ${ }^{53}$ Sem cultivar sua propriedade, podemos supor que tencionasse vendê-la e que a oferta de tal extensão de terras interessou Perret Gentil, em busca de uma propriedade que atendesse seus planos de constituir um empreendimento de colonização.

Assim, Perret Gentil, por ocasião de seu desembarque no litoral paranaense, apresentou ao comendador Manoel Antônio Guimarães, o maior exportador de erva-mate do Paraná e um dos potentados locais, ${ }^{54}$ uma autorização de David Stevenson para estabelecer-se na península de Superagui em conjunto com o grupo de colonos. O comendador elogiara a escolha da região pelo cônsul suíço para a fundação do estabelecimento, tendo em vista sua extensão - cinco léguas defronte ao mar, três de fundo - e pela abundância de madeiras. Entretanto, a região ainda não era propriedade de Perret Gentil, obrigando-o ir ao Rio de Janeiro para comprá-la de Stevenson, logo após ter deixado seus colonos para dar início aos trabalhos. Caso não o conseguisse, Manoel Antônio Guimarães sugeria outras regiões ao norte da Baía de Paranaguá, como o leito dos rios de Guaraqueçaba, Grogossu ou Tagaçaba: "Não será pois pela falta de terrenos adquados em pozição e qualidade, que o ensaio collonial do Snr ${ }^{\circ}$ Perret Gentil deixará de prosperar". ${ }^{5}$

\footnotetext{
${ }^{52}$ LOPES, José Carlos Veiga. Superagui: Informações Históricas. Curitiba: Instituto Memória, 2009, p. 85-92.

${ }^{53}$ PLATZMANN, Julius. Da Baía de Paranaguá. Curitiba: Edição do tradutor, 2010, p. 80.

${ }^{54}$ OLIVEIRA, op. cit., p. 150.

${ }^{55}$ GUIMARÃES, Manoel Antonio. Correspondência enviada ao Presidente da Província de São Paulo. Paranaguá, 26 de janeiro de 1852. Arquivo Público do Estado de São Paulo (AESP), Acervo Império (1822-1889), ofícios
} 
Porém, o cônsul suíço logra a região pretendida, em 14 de janeiro de 1852, arrematando-a por 6:500\$000 réis, pagáveis em duas prestações no decorrer de três anos. ${ }^{56} \mathrm{Em}$ Superagui, Perret Gentil decidiu por instalar-se no limite setentrional de sua propriedade, próximo à Baía dos Pinheiros e à Ilha das Peças, às margens do Rio Segredo. Lá construiu seu engenho de beneficiamento de diversos produtos coloniais. Parece-nos que a totalidade dos colonos e moradores brasileiros de Superagui se instalou às margens do referido canal, via de comunicação com a Baía de Paranaguá e de mais facilidade no trato agrícola.

Desvencilhando-se das ocupações que podiam obstar sua nova empresa, ${ }^{57}$ Perret Gentil procedeu ao aliciamento de novos colonos estrangeiros. Começara seu estabelecimento com apenas cinco famílias, quando chegara em outubro de 1851 . No decorrer do ano de 1852, recebera poucos colonos solteiros e algumas famílias, em sua maioria de origem suíça, embora houvesse alguns franceses e um dinamarquês. Por fim, um dos habitantes brasileiros da região tornou-se colono na mesma época: era Antônio Rosa, admitido em 1852, e que acabaria por se tornar o primeiro proprietário definitivo entre os colonos de Superagui.

É difícil precisar os meios de recrutamento lançados à mão por Perret Gentil para angariar colonos, mas podemos supor que tais indivíduos não imigraram com sua passagem financiada pelo empreendimento de Superagui, mas sim espontaneamente. Os registros do colono suíço Guillaume Henri Michaud, mais conhecido como William Michaud, esclarecendo suas motivações em emigrar para o Brasil, são os únicos conhecidos e preservados, fornecendo-nos embasamento suficiente para tais conclusões. Michaud era natural da cidade de Vevey, na Suíça francófona, e desembarcou no Rio de Janeiro em $1^{\circ}$ de fevereiro de 1849 , com proposta de trabalho numa grande propriedade fluminense para a cultura do bicho da seda. Após um ano e meio,

\footnotetext{
(1852-1872) Paranaguá, CO1144.

${ }^{56} 2^{\circ}$ TABELIONATO DA CIDADE DO RIO DE JANEIRO. Auto de Arrematação da Fazenda do Superagui. Rio de Janeiro, 14 de janeiro de 1852. Arquivo Nacional - Livro 169, p. 68v-69.

${ }^{57} \mathrm{~A}$ fábrica que possuía em Campos acabou sendo transferida para o inglês Samuel Henshel, encontrando-se em atividade no ano de 1856.0 cargo de cônsul geral que possuía transferiu apenas em 1853 a Jean François Emery, também negociante suíço no Rio de Janeiro, partícipe de casas de comissão e bancos Durante os anos de 1851 e 1852, servira interinamente, sendo efetivado cônsul em 1853. Em 1855, falira o banco a seu cargo e fora afastado do consulado pela acusação de roubo de caixa. Cf. RIO DE JANEIRO. Relatorio apresentado ao Excellentissimo Vice-Presidente da Província do Rio de Janeiro o senhor conselheiro Antonio Nicoláo Tolentino pelo presidente o conselheiro Luiz Antonio Barbosa sobre o estado da administração da mesma Província. Rio de Janeiro: Typographia Imperial e Constitucional de J. Villeneuve e Comp., 1856, p. 59. VEYRASSAT, op. cit., p. 15; TSCHUDI, Johann Jakob Von, Rapport de Mr. de Tschudi, Envoyé extraordinaire..., op. cit., p. 277.
} 
em virtude de problemas no cultivo e de pagamento, abandonara o empreendimento. Charlez Pradez, o comerciante suíço responsável pela sua vinda ao Brasil, sugeriu-lhe que procurasse ocupação em outras empresas suíças. ${ }^{58}$ Pelo exemplo podemos supor um padrão de aliciamento de colonos para Superagui: indivíduos vindos às próprias expensas, engajados em função das ligações de Perret Gentil com seus compatriotas negociantes.

FIGURA 1 - Mapa da Colônia de Superagui. Conforme podemos ver na imagem abaixo, o núcleo colonial ocupava a maior parte da península de Superagui e a parte sul da Ilha das Peças.

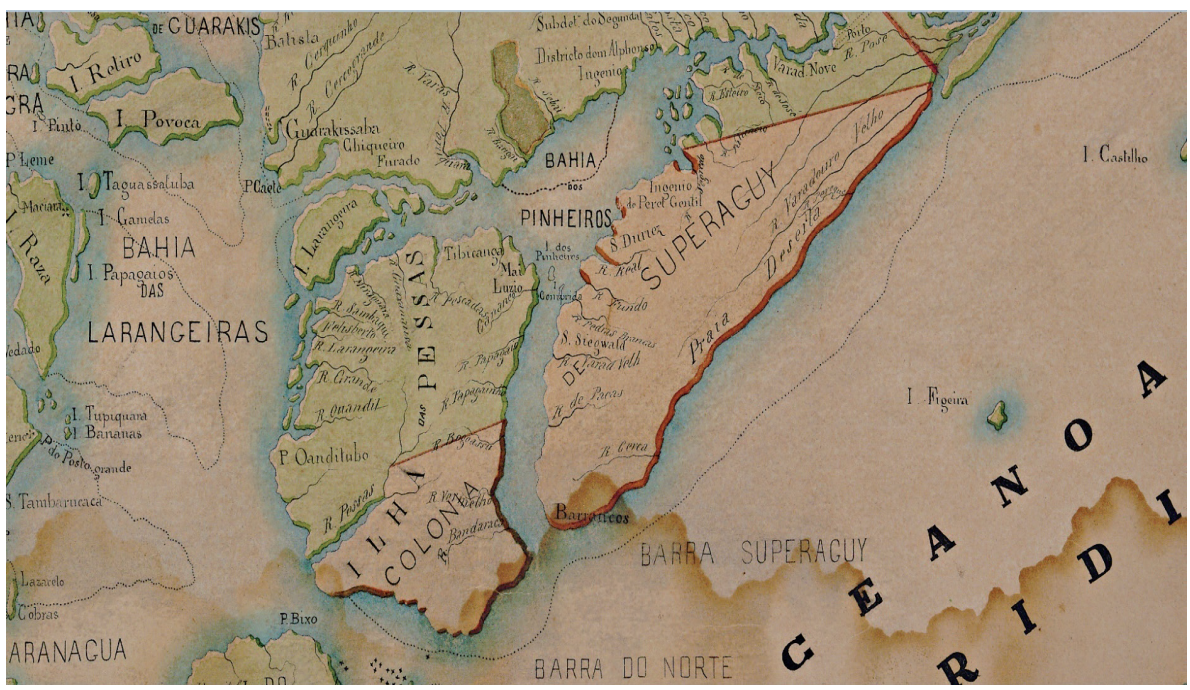

Fonte: BRASIL. Mappa das Bahias de Paranaguá comprehendendo a Colônia de Superaguy Entrada do Mar Pequeno de Iguape. Rio de Janeiro: Archivo da S. de Desenho, 1870. Arquivo Nacional: 4M.0.MAP.163.

Ao mesmo tempo em que Perret Gentil recebia novos indivíduos, outros abandonavam o empreendimento. No primeiro ano de instalação de Superagui, o núcleo recebeu 20 colonos, somando-se aos vinte já existentes em junho de 1852, dos quais se evadiram nove, o que fez Manoel Antônio Guimarães suspeitar do sucesso da empresa. Os colonos ainda não haviam exportado nada, com exceção de três navios carregados de madeira. Guimarães

\footnotetext{
${ }^{58}$ MICHAUD, William; LAMBERT, Françoise. Chère soeur [Emma] Vevey, le 28 octobre 1848; Cher père, Rio de Janeiro, le 24 août 1850. William Michaud [(1829-1902)]: lettres, dessins et aquarelles d'un émigrant vaudois au Brésil. Vevey: Musée historique, 2002, p. 39; 53.
} 
afirmava, inclusive, que desconhecia os "contractos que tem os Collonos com o proprietario, com que condição são admitidos na Collonia, que sistema de trabalho é ahi admitido, e se esse trabalho é proprio do Collono ou do empresario para haver o interesse da terra ou vantagem do Capital que entregou". ${ }^{59}$

o potentado parnanguara defendeu que o empreendimento poderia trazer progresso à região, mas que arriscava extinguir-se por má administração. ${ }^{60}$ Tais impressões reverberam em relatório da Presidência da Província de São Paulo, sublinhando que a colônia não prosperava e seus colonos plantaram apenas para subsistência. ${ }^{61}$ Estaria nos primeiros anos de Superagui já bem estabelecida a impressão sobre o núcleo colonial: uma empresa que não prosperava e dificilmente lograria algum resultado. O relatório da Repartição Geral das Terras Públicas repetiria a mesma ideia poucos anos depois, afirmando laconicamente que o núcleo: "pouco promette". ${ }^{62}$

\section{E os colonos parceiros tornam-se pequenos agricultores}

Observamos acima a defesa de Perret Gentil ao "sistema Vergueiro" e sua intenção de adotá-lo em seu próprio empreendimento de colonização. Como destacado acima, as experiências de colonização no Brasil meridional não se pautaram pelo emprego de colonos assalariados em grandes propriedades exportadoras, tal como na parceria, mas sim pela venda de terrenos aos adventícios. Procederia a Colônia de Superagui aos seus desígnios originais? Isso será observado logo abaixo.

Mesmo após a fundação de Superagui, Perret Gentil teria defendido que sim, seu empreendimento seguia as bases do que vira na propriedade da família Vergueiro. As afirmações nesse sentido não saíram de seu próprio punho, mas de outrem. Uma obra panfletária é publicada na Europa promovendo a emigração para o Brasil, principalmente para Ibicaba e, com menos ênfase, para a colônia de Superagui: é o opúsculo "Le Brésil en 1852 et as Colonisation Future", de autoria de Jean-Louis Moré. Na parte que trata de

\footnotetext{
${ }^{59}$ GUIMARÃES, Manoel Antonio. Correspondência enviada ao Presidente da Província de São Paulo. Paranaguá, 3 de janeiro de 1853. Arquivo Público do Estado de São Paulo (AESP), Acervo Império (1822-1889), Ofícios (1852-1872) Paranaguá, CO1144.

${ }^{60}$ Idem.

${ }^{61}$ SÃO PAULO. Relatorio com o que o Illustrissimo e Excellentissimo Senhor Dr. Josino do Nascimento da Silva Presidente da Provincia de S. Paulo abrio a Assembléa Legislativa Provincial No dia 16 de fevereiro de 1853. São Paulo: Typographia 2 de Dezembro, 1853, p. 11.

${ }^{62}$ BRASIL. Relatório apresentado á Assembléa Geral Legislativa na Terceira Seção da Nona Legislatura pelo Ministro e Secretario de Estado dos Negocios do Imperio Luiz Pedreira do Couto Ferraz. Rio de Janeiro: Typographia Universal de Laemmert, 1855. N.1 Mappa Estatistico das Colonias Existentes no Império.
} 
Ibicaba, Moré copiou integralmente boa parte das informações descritas pelo antigo cônsul em seu livro "A Colonia Senador Vergueiro: Considerações". 0 capítulo que se destina a Superagui é o único que recebe o nome da colônia e de seu diretor no título, chegando Moré inclusive a afirmar que Perret Gentil era seu "estimável amigo". ${ }^{63}$

De acordo com "Le Brésil en 1852...", os princípios que norteavam Superagui seriam os mesmo praticados em Ibicaba: "tudo isto que relatamos com a mais exata fidelidade da colônia Vergueiro, bem como de outras Fazendas, existe realmente na colonização de Superagui". ${ }^{64}$ De acordo com o opúsculo, posterior a fundação do núcleo:

Após ter estudado com cuidado e a fundo os diversos sistemas de colonização em uso no Brasil, após ter dado uma larga preferência àquele do Vergueiro, é em pleno conhecimento de causa que o proprietário de Superagui agiu, outrossim introduziu, assim como dissemos em outra parte, todas as modificações e melhorias as quais este sistema pode ser suscetível. ${ }^{65}$

O trecho em referência destaca que, embora a empresa colonial fosse inspirada no modelo do senador Vergueiro, haveria modificações que tornariam os acordos praticados em Superagui diferentes daqueles firmados em Ibicaba. A principal modificação, um verdadeiro anátema para os cafeicultores paulistas, consistia na venda de lotes de terra aos colonos, tornando-se tal prática o cerne das formas de engajamento para o núcleo colonial. Perret Gentil pretendia comercializar na Europa parcelas de sua propriedade para que os colonos viessem a se instalar nela. $O$ terreno a ser vendido seria de quinze hectares, tamanho pequeno para os padrões de colonização ao sul do Brasil, ${ }^{66}$ pelo valor de mil francos (algo entre $333 \$ 000$ e $360 \$ 000$ réis). Outra oferta aos postulantes à colônia seria o aforamento dos terrenos, com custo anual entre 60 e 30 francos (algo entre $21 \$ 600$ e $9 \$ 900$ réis), de acordo com as medidas do lote colonial, também diminutos para os padrões da colonização europeia dos oitocentos. ${ }^{67}$ Tais acordos de concessão de terras não pressupunham a divisão do produto da venda dos gêneros coloniais, tal como na parceria, pertencendo ao colono toda a produção decorrente de seu trabalho.

\footnotetext{
${ }^{63}$ MORÉ, Jean-Louis. Le Bresil en 1852 et sa Colonisation Future. Geneve: Chez les Principaux Libraries, 1852, p. 222.

${ }^{64}$ Ibidem, p. 225 (tradução livre).

${ }^{65}$ Ibidem, p. 230-231.

${ }^{66}$ SEYFERTH, Giralda. A colonização alemã no Brasil: Etnicidade e Conflito. In: FAUSTO, Boris (org.). Fazer a América. São Paulo: Edusp, 1999, p. 279.
}

${ }^{67}$ Ibidem, p. 232. 
Acordo semelhante à parceria restringiu-se apenas a uma oferta de trabalho em Superagui veiculada na referida fonte, ainda assim, sem grande alarde.

Não havia nada mais distante da mentalidade dos fazendeiros do Oeste Paulista que a concessão ou venda de lotes de terra aos colonos europeus, sendo o próprio senador Vergueiro contrário à iniciativa. Devia-se antes solucionar a falta de braços para a lavoura em expansão, e não desviar um contingente propício à faina nas grandes propriedades, fornecendo-lhes lotes de terra. ${ }^{68}$ Entretanto, a família Vergueiro, por mais que fosse contrária à colonização oficial, não deixaria de estimular em parte alguns de seus princípios, pois, conforme vimos, fornecia aos imigrantes engajados uma pequena extensão de terra em suas propriedades para cultivo de gêneros, apresentando a parceria como uma síntese entre os dois projetos. ${ }^{69}$ A perspectiva de que o parceiro não seria apenas um lavrador proletarizado, mas teria acesso a um pedaço de terra para cultivo ${ }^{70}$ tal como nas colônias de pequenos proprietários, é um dos pontos de tangência entre a experiência de Ibicaba e a de Superagui, e talvez o elemento dos acordos de parceria que estimulou Perret Gentil no desenvolvimento de seu núcleo, sendo uma das poucas características correlatas à experiência da lavoura paulista.

Tendo por base um elemento secundário dos acordos de parceria assim presume-se - Carlos Perret Gentil daria um passo à frente nos acordos existentes na lavoura paulista, não apenas cedendo para uso parcelas de sua propriedade, mas vendendo-as aos imigrantes engajados - e, dessa forma, alterando a essência do empreendimento ao qual até então se reportava. Em seus escritos, o antigo cônsul observou que a maioria dos imigrantes tinha a pretensão de adquirir um terreno próprio para o cultivo, algo que reprovava, uma vez que as dificuldades de estabelecimento faziam os colonos retornarem às colônias de parceria, nas quais conseguiam prosperar. ${ }^{71}$ Portanto, a transformação proposta para os arranjos de trabalho de Superagui tinha por fim satisfazer a principal "ambição" e o "desideratum" dos adventícios, transformando-os em proprietários de seu quinhão de terras, perspectiva partilhada por diversos empreendedores imigrantistas. ${ }^{72}$

\footnotetext{
${ }^{68}$ HOLLANDA, op. cit., p. 245.

${ }^{69}$ Ibidem, p. 249.

${ }^{70}$ MARTINS, José de Souza. O Cativeiro da Terra. São Paulo: LECH - Livraria Editora Ciências Humanas, 1981, p. 74

${ }^{71}$ GENTIL, A Colônia Senador Vergueiro..., op. cit., p. 65.

${ }^{72}$ HALL, Michael McDonald. The Origins of Mass Imigration in Brazil, 1871-1914.194 f. Tese (Doutorado em Ciência Política). Columbia University, 1969, p. 61; PETRONE, Maria Thereza Schorer, op. cit., p.47.
} 
O opúsculo "Le Bresil en 1852 et as Colonisation Future" destaca outro anúncio que endossa a ligação entre José Vergueiro e Perret Gentil, esta laureada também por referências ao sistema praticado na propriedade da família paulista. De acordo com a obra, ambos formaram uma companhia de imigração que, entre as atividades, oferecia emprego "em uma colônia situada sobre a costa do mar, a 75 léguas do Rio de Janeiro", na qual os colonos trabalhariam à 'metade do fruto' e, num prazo de cinco anos, receberiam um lote de terras comunais de dez hectares ou, caso preferissem pagar pelo lote, "todo o produto de seu trabalho ser[ia] sua propriedade exclusiva". ${ }^{73} \mathrm{O}$ contrato da tal companhia com os colonos engajados também previa a venda de lotes para aqueles que já possuíssem recursos suficientes.

Com o fim de angariar fundos e intermediar vendas de terras na Europa, Perret Gentil também obteve o apoio de Robert Melly, sócio da casa bancária suíça George \& Robert Melly Cie, que viria a se instalar no empreendimento de Superagui. Sócio na empresa junto com o antigo cônsul, Robert Melly defendia a emigração e o fornecimento de terras alhures a preços módicos para combater o fenômeno do pauperismo e a pobreza da classe trabalhadora no continente europeu. ${ }^{74}$ Assim sendo, a emigração das classes mais desfavorecidas deveria ter como objetivo, além de 'melhorar' a vida dessas pessoas, afastá-las da influência do comunismo, "a mais indigna teoria, o mais reprovável dos sistemas", ${ }^{75}$ em função do qual os países europeus eram forçados a "derramar ao longe seu excedente de população e de forças, a fim de evitar toda perturbação nas relações do próprio país". ${ }^{76}$ No intuito de custear o transporte de possíveis emigrantes, o banqueiro suíço expediu uma circular para atrair investidores que pudessem fazer adiantamentos à expedição com vistas ao Brasil. Os capitais seriam retornados ao final de quatro anos, a juros anuais de $4 \%$, restituindo-se a quarta parte dos adiantamentos ao final de cada ano do acordo. Nos arranjos de parceria, eram necessários capitais europeus para o custeio das passagens dos imigrantes, fornecidos em primeira

\footnotetext{
${ }^{73}$ MORÉ, op. cit., p. 314-315.

${ }^{74}$ Sobre a questão do pauperismo, a pobreza dos trabalhadores europeus e a relação de ambos com a emigração européia, Cf. CASTEL, Robert. Uma Política sem Estado. In: As Metamorfoses da Questão Social. Petrópolis: Vozes, 1995, p. 284-287; HOBSBAWN, Eric. Os Trabalhadores Pobres. In: A Era das Revoluções. Rio de Janeiro: Paz e Terra, 1991, p. 226; ___. Os Homens se Põem a Caminho. In: A Era do Capital. Rio de Janeiro: Paz e Terra, 1988, p. 212-213.

${ }^{75}$ MORÉ, op. cit, p.282.

${ }^{76}$ Ibidem, p. 283.
} 
instância pelas municipalidades europeias, expediente ao qual recorreriam outras empresas de colonização. ${ }^{77}$

Posteriormente, Robert Melly renovaria mais uma vez as tentativas de comercialização dos terrenos de Superagui na Suíça, utilizando-se para tal de anúncios em jornais. Em 1853, intercedia Perret Gentil na venda de quatro lotes de terra na colônia de Paranaguá, aludindo as suas vantagens naturais, como seus terrenos férteis e abundância de água e madeira, bem como as possibilidades de valorização no decorrer dos anos.

NÈVE.

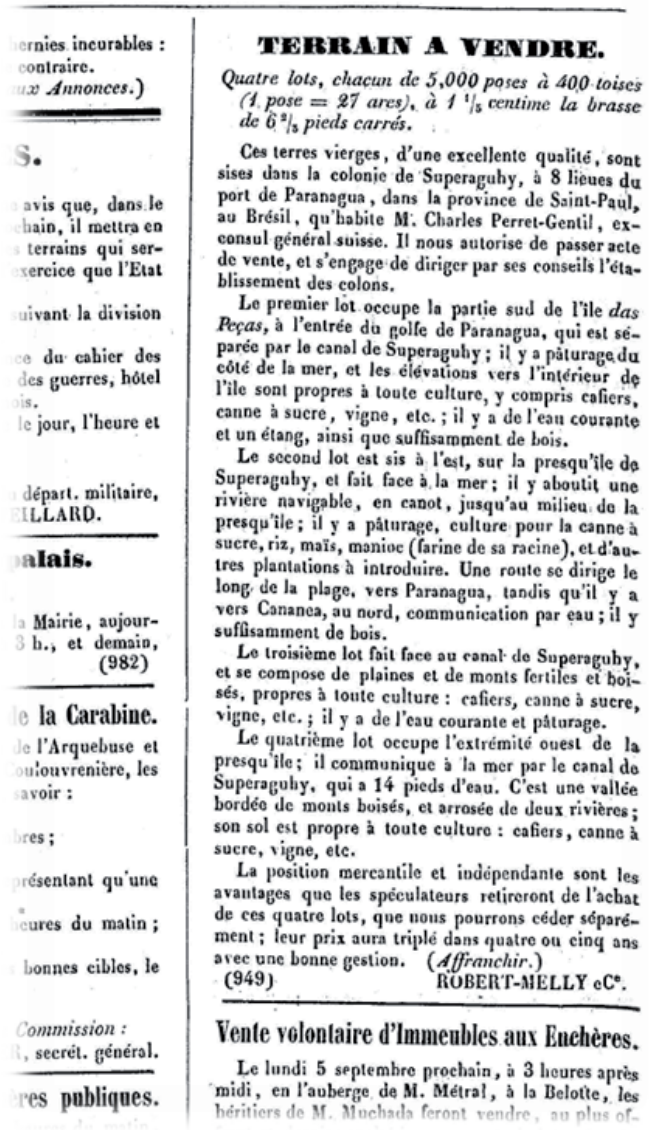

FIGURA 2: Anúncio de venda de terras em Superagui no Journal de Genève.
FONTE: Terrain a Vendre. Journal de Genève.Genebra, 21 ago. 1853, p. 4. Dispo-nível em: http:// www.letempsarchives.ch/ Default/Skins/LeTempsFr/ Client.asp?Skin=LeTempsFr \&enter=true \&AppName $=2 \&$ $\mathrm{AW}=1343222359111$. Acesso em: 25/07/2012.

${ }_{77}$ Cf. RICHTER, Klaus. A Sociedade Colonizadora Hanseática de 1897 e a colonização no interior de Joinville e Blumenau. Florianópolis: Editora da UFSC, 1986, p. 23-24. 
Os diversos anúncios de venda das terras na península de Superagui são indicativos das transformações sofridas no projeto inicial de Perret Gentil. Não mais o contrato de trabalhadores parceiros proletarizados, mas o emprego do contingente europeu como pequeno agricultor e dono de seu próprio quinhão de terra. Nesse sentido, o antigo cônsul suíço definiria o 'sistema' de trabalho introduzido em sua propriedade, cujo teor consistia em "aforar ou vender os lotes de terra [aos colonos], os productos são em totalidade para elles, a unica obrigação que os liga comigo alem da divida e dar me a preferencia para me vender ou fazer preparar o producto a igualdade de preço". ${ }^{78}$ Por essa época, não são mais feitas referência ao "sistema Vergueiro" e nem mesmo críticas às formas de emprego do contingente imigrante em outras colônias diferentes daquelas praticadas na lavoura paulista, mas a defesa do procedimento adotado por Perret Gentil para seu empreendimento. A experiência de Superagui, no fundo, tornava-se semelhante a outros empreendimentos congêneres no tempo e no espaço, como as colônias Dona Francisca e Blumenau, ou mesmo a colônia Thereza: o fornecimento de lotes de terra a colonos europeus para que fossem pequenos "proprietários".

Indicamos acima que a venda de terrenos em Superagui poderia provir de uma característica dos acordos praticados nas grandes fazendas de São Paulo, que era a cessão de um pedaço de terra para uso pessoal do colono posto então à venda ou aforado em Superagui. Outra característica do arranjo de trabalho paulista colocada em prática na colônia parnanguara com leve reminiscência do sistema de parceria diz respeito ao pertencimento ao próprio colono do fruto de seu trabalho. Conforme Perret Gentil escrevera, pelo sistema Vergueiro ao fazendeiro e ao imigrante caberia a 'metade do fruto' da venda do café, não podendo este ser comercializado de forma independente pelo colono. Em Superagui, os colonos engajados poderiam comercializar os gêneros que produziam, pertencendo-lhes assim todo o fruto de seu trabalho, interferindo Perret Gentil de maneira menos acentuada na produção desses trabalhadores, sendo apenas um comprador privilegiado de tais mercadorias. Como se processaria a aquisição da produção dos imigrantes pela administração colonial nos parece obtuso, talvez por uma compra consignada do diretor da colônia, mas é demonstrativo do pouco controle da produtividade e da preferência em auferir ganhos principalmente com a venda de terras.

Chama-nos a atenção a insistência na denominação dos acordos de trabalho como ‘sistema'. A Colônia Thereza seguia por linhas parecidas. O Dr.

${ }_{78}$ GENTIL, Carlos Perret. Ofício para o Presidente Zacarias de Góes e Vasconcellos. Superagui, 22 fev. 1854. Arquivo Público do Paraná, AP - 3, folhas 207-213. 
Faivre alegava que o sistema pelo qual os trabalhos eram encaminhados no núcleo consistia em fornecer gratuitamente aos colonos um terreno por volta de 500 braças quadradas para erguer sua moradia e mais 30 mil braças quadradas de terrenos lavradios. A administração colonial fazia os adiantamentos em víveres para os primeiros anos de moradia, devendo os colonos saldar os avanços em quatro anos. A adesão a tal projeto implicava obrigações como gramar os terrenos dos pastos comuns ou manter uma produção constante de mantimentos.$^{79} \mathrm{O}$ regulamento de terras do Paraná, produzido em 1893, ainda se referiria ao engajamento de trabalhadores para as propriedades rurais como 'sistema', arranjos tais como salário, empreitada e parceria. ${ }^{80}$

As cadeias de endividamento, seja pela aquisição de lotes ou adiantamento de gêneros, eram elementos correlatos ao sistema de parceria, embora fossem presentes em diversos empreendimentos de colonização - a "dívida colonial”, cuja cobrança dos colonos foi muitas vezes protelada. ${ }^{81} \mathrm{Um}$ último elemento no qual constatamos a influência da grande lavoura é a cultura que seria a principal fonte de dividendos de Superagui: o café. Perret Gentil declarara certa vez que era necessário manter os possíveis imigrantes próximos aos centros de riqueza, cultivando os gêneros que dão maiores rendimentos ao Império do Brasil. E o cultivo do café em si não chegava a ser uma grande novidade na região. Vimos acima que os ingleses de Superagui mobilizaram sua escravaria com vistas à cafeicultura. O relatório de polícia apresentado na ocasião da emancipação da Província já indicava que um dos produtos agrícolas mais cultivados na região de Guaraqueçaba era justamente o café. ${ }^{82}$

\section{Considerações finais}

Aos olhos contemporâneos, quando se pensa sobre a possibilidade do empreendimento de colonização da península de Superagui ser inspirado na iniciativa havida na fazenda de Ibicaba, tal como defendeu o cônsul da Suíça, Carlos Perret Gentil, o primeiro elemento que deveria ser destacado da experiência inspiradora é justamente o seu sistema de trabalho, o regime de parceria.

\footnotetext{
${ }^{79}$ FAIVRE, João Mauricio. Correspondência enviada ao Presidente de Província do Paraná..., op. cit.

${ }^{80}$ PARANÁ. Secretaria D’Estado dos Negocios das Obras Publicas e Colonização. Decreto N.1, de 8 de abril de 1893. Curitiba; Typographia D’A Republica, 1893. Anexo: Modelo de um processo de discriminação de terras em conformidade com o Regulamento a que se refere o decreto N.1 de 8 de abril de 1893, p. 12.

${ }^{81}$ BALHANA, Política Imigratória no Brasil Meridional, op. cit., p. 141-142; LAMB, Robert Edgar. Uma Jornada Civilizadora: Imigração, Conflito Social e Segurança Pública na Província do Paraná - 1867 a 1882. Dissertação (Mestrado em História). Universidade Federal do Paraná, Curitiba, 1994, p. 67.

${ }^{82}$ Polícia. Dezenove de Dezembro, Curitiba, N³4, 18 de Novembro de 1854, p. 3
} 
De fato, o empresário fundador da colônia às margens da Baía de Paranaguá defendeu que seu objetivo seria justamente se dedicar à agricultura sob as bases do sistema idealizado pela família Vergueiro. A referência é defendida após a fundação do núcleo, mas os acordos de trabalho que seriam o cerne da empresa são esquecidos e relegados a segundo plano. Pode-se inferir que a reiteração desse pressuposto fosse de grande valia ao antigo cônsul suíço, uma vez que sua empresa, de pequenas dimensões, quando comparada a outra de grande vulto e importância, adquirisse o mesmo prestígio e atenção das iniciativas do Oeste Paulista. Assim, a ligação sempre referenciada exercia mais uma função retórica de enaltecimento do núcleo colonial do antigo cônsul, ao invés de definir os arranjos de trabalho lá havidos.

Sob o ponto de vista contemporâneo pode parecer contraditório o desenvolvimento de Superagui, mas sob uma interpretação coetânea, dos agentes históricos que vivenciaram tais acontecimentos, talvez não o fosse. Uma imigração destinada à grande lavoura para engajamento de imigrantes como trabalhadores livres, e uma colonização que pretendia fornecer lotes de terras a estrangeiros, talvez não fosse tão antitética como pareceu aos olhos da historiografia do século XX. ${ }^{83}$ Por mais que aos agentes históricos coetâneos houvesse de fato uma diferença entre os dois empregos da mão de obra adventícia, a palavra que definia ambas as iniciativas era 'colonização', tanto que o imigrado era sempre denominado colono, seja na lavoura paulista ou em uma colônia de pequenos proprietários. Colonização - a atividade de ocupar terras e controlar populações com o objetivo de extrair riquezas ${ }^{84}$ conseguia exprimir os dois sentidos de emprego da população imigrante. É um caso no qual o significado coetâneo de uma expressão utilizada no passado possui sentidos diferentes e menos específicos daqueles que lhe seriam atribuídos no futuro ${ }^{85}$ - colonização, de acordo com a historiografia dedicada ao tema, referir-se-ia apenas ao estabelecimento de imigrantes como pequenos agricultores e proprietários.

Por fim, deve-se sublinhar que as transformações no projeto original de organização da colônia de Superagui são correlatas às transformações nos contratos de trabalho em uso na grande lavoura e mesmo nos significados

\footnotetext{
${ }^{83}$ Sobre os conceitos antitéticos, conferir KOSELLECK, Reinhard. Futuro Passado: contribuição à semântica dos tempos históricos. Rio de Janeiro: Contraponto, 2006, p. 191-197.

${ }^{84}$ BOSI, Alfredo. Dialética da Colonização. São Paulo: Companhia das Letras, 1992, p. 11-12.

${ }^{85}$ RUSEN, Jorn. Razão Histórica: teoria da história: fundamentos da ciência histórica. Brasília: Editora Universidade de Brasília, 2001, p. 111-112. Sobre a relação e sinonímia entre os dois sentidos, conferir MEDONÇA, op. cit., p. 220-221.
} 
atribuídos ao próprio sistema de parceria. Os diferentes problemas havidos com os colonos parceiros na década de 1850 suscitaram modificações nos arranjos de trabalho: não haveria mais a divisão da venda de café a razão de $50 \%$ entre trabalhador e fazendeiro, mas preferencialmente a retribuição fixa por arroba de café colhida pelo colono. A parceria, por sua vez, passou a significar arranjos de trabalho nos quais haveria a divisão bruta da produção obtida, não havendo mais a comercialização dos produtos da lavoura apenas pelo fazendeiro. Pela modificação, fazendeiro e trabalhador seriam responsáveis pela comercialização de seu respectivo quinhão de gêneros. ${ }^{86}$ Assim, a modificação do sistema de trabalho na Colônia de Superagui, feita de chofre, já em seus inícios, seguiu padrão observável nos arranjos de trabalho da grande lavoura.

Artigo recebido para publicação em 30/09/2017

Artigo aprovado para publicação em 04/12/2017

${ }^{86}$ CANDIDO, Antonio. Os parceiros do Rio Bonito: estudo sobre o caipira paulista e a transformação dos seus meios de vida. São Paulo: Editora 34, 2001, p. 136-137; MATTOS, Hebe Maria; RIOS, Ana Maria. Para além das senzalas: campesinato, política e trabalho rural no Rio de Janeiro pós-Abolição. In: CUNHA, Olívia Maria Gomes da; GOMES, Flávio dos Santos (Org.). Quase-Cidadão. Histórias e antropologias da pós-emancipação no Brasil. Rio de Janeiro: Editora FGV, 2007, p. 68-69. 